\title{
Graphite-Nimonic alloy brazing
}

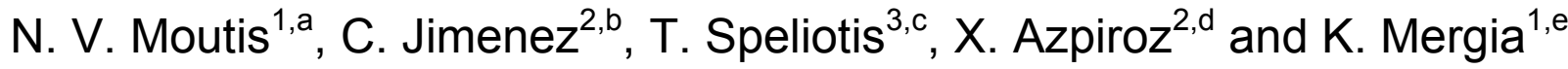 \\ ${ }^{1}$ Institute of Nuclear Technology and Radiation Protection, NCSR “Demokritos”, 15310 Aghia \\ Paraskevi, Athens Greece \\ ${ }^{2}$ Fundación INASMET, Parque Tecnológico, E-20009 San Sebastian , Spain \\ ${ }^{3}$ Institute of Material Science, NCSR “Demokritos”, 15310 Aghia Paraskevi, Athens, Greece \\ anmoutis@ipta.demokritos.gr, bcristina.jimenez@inasmet.es, 'speliotis@ims.demokritos.gr, \\ dxazpiroz@inasmet.es, ${ }^{e}$ kmergia@ipta.demokritos.gr,
}

Keywords: Graphite; Brazing; Nimonic alloys; Chromium carbide.

\begin{abstract}
A graphite sheet has been successfully brazed to a Nimonic 105 superalloy using a commercial TiCuSil paste. A chromium layer was deposited on the graphite surface by sputtering and controlled heat treatments were employed in order to develop a suitable microstructure. Scanning electron microscopy measurements showed rough, crack-free interfaces between the filler metal and both the graphite and nimonic parts. From metallographic examination a well defined layered structure of the metallic elements close to the filler/graphite interface has been found. The metallic elements transport from the interface to the carbon bulk where they fill all the graphite pores up to a depth up of $50 \mu \mathrm{m}$ and form a layered structure within the pores.
\end{abstract}

\section{Introduction}

Advanced carbon or carbon composite materials are widely used in aerospace or other technological sectors as fusion and fission $[1,2,3]$. Joining of these ceramic materials to metals is required in a number of advanced applications and in many cases these joints have to operate at extreme environments as high temperatures, oxidizing and corrosive atmospheres and under mechanical loads. Successive thermal cycles may generate aging and failure of the joint due to large internal stresses arising from the different thermal expansion coefficients (CTE) of such dissimilar materials. Thus, a modification of the composite surface is important in order to compensate the large CTE mismatch [4]. Further, such a surface modification should assure good adhesion to the ceramic, high temperature phase stability and mechanical strength. Matching of the CTE's requires a graded layer structure which should survive during the joining process and under service conditions.

The work presented here, is the first part of a generic approach for joining industrially produced $\mathrm{C}_{\mathrm{f}} / \mathrm{C}$ or $\mathrm{C}_{\mathrm{f}} / \mathrm{SiC}$ composites to alloys which are of interest to aerospace industry. This approach consists in metallizing the composite surface and, through controlled annealing, in producing a graded film structure strongly bonded to the ceramic. Then, the final optimized structure can be tested by joining it to a metal. Under the above premises commercially available graphite sheet has been chosen for the ceramic part. Carbon materials are of interest to many technological fields, e.g. fusion. However, the choice of graphite was mainly made in order to understand the surface interactions in a simpler structure before attempting to apply this approach to composite structures in which the reactions of both the fibres and the matrix have to be taken into account. As a metallizing species $\mathrm{Cr}$ was chosen, as it is a strong carbide former [5]. The $\mathrm{Cr}$ was deposited on the graphite by sputtering because this technique allows good control of the film microstructure and thickness. Through a series of vacuum heat treatments the most promising metal-graphite structure was brazed to a Nimonic 105 superalloy. Joining was performed by the use of TiCuSil filler metal. TiCuSil is a commercially available braze filler and it has been applied for joining carbon composites to different metals $[4,6,7,8]$. The produced joint was crack-free and a good wetting 
behavior on both the superalloy and the graphite has been observed. Each stage of the processing was monitored by X-ray diffraction and scanning electron microscopy measurements.

\section{Experimental}

Commercially available rigid graphite sheets (Goodfellow), purity $99.95 \%$, were selected as the ceramic part. A chromium layer, having a nominal thickness of $2 \mu \mathrm{m}$, was deposited by magnetron sputtering at nearly ambient temperature $\left(70^{\circ} \mathrm{C}\right)$. A 2 "-diameter $\mathrm{Cr}$ target of $99.95 \%$ purity was used. The base pressure before introducing the Ar gas was $1 \times 10^{-6} \mathrm{mbar}$ and the pressure during deposition was $4 \times 10^{-3}$ mbar. Depositions were performed using a DC power of $120 \mathrm{~W}$, resulting in a deposition rate of $17 \AA / \mathrm{s}$.

Post deposition thermal annealing was performed to the $\mathrm{Cr} / \mathrm{C}$ structure in order to form a chromium carbide layer at the $\mathrm{Cr} / \mathrm{C}$ interface (Fig. 1, left). The samples were enclosed in a quartz tube and they were annealed in a tubular furnace at $700{ }^{\circ} \mathrm{C}$ for various times under high vacuum $\left(10^{-}\right.$ ${ }^{6}$ mbar).

The modified ceramic was brazed to a Nimonic 105 superalloy using an IPSEN VFCK-124 high vacuum furnace and the thermal cycle presented in Fig. 1. Nimonic 105 is a wrought nickel-cobaltchromium base alloy strengthened by additions of molybdenum, aluminum and titanium. It has been developed for service up to $950{ }^{\circ} \mathrm{C}$ and combines high strength and good creep resistance. The interlayer (filler) metal, TiCuSil alloy (Ag-26.7Cu-4.6Ti wt.\%) in paste form (Wesgo Metals), was applied for joining the two parts (Fig.1, left).
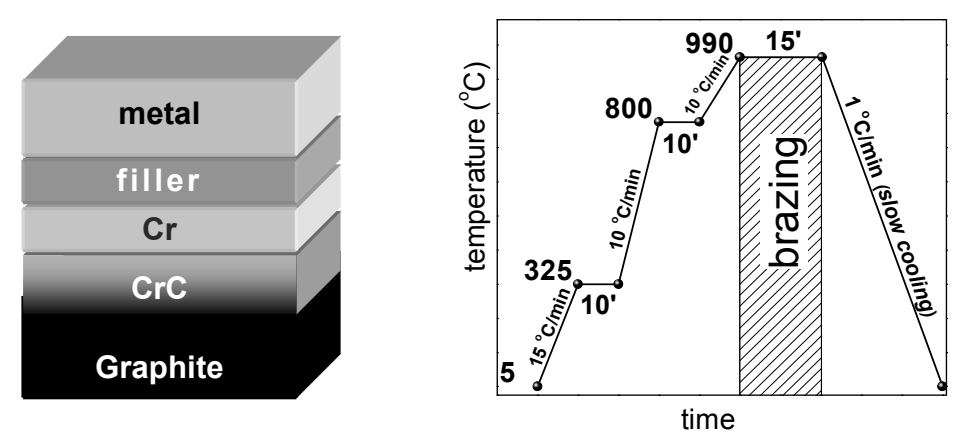

Fig. 1. Left: Schematic of the metal-ceramic joint. Right: Thermal cycle of brazing.

X-ray diffraction spectra were collected in the $2 \theta$ range $10-90^{\circ}$ using a Siemens D500 diffractometer and a $\mathrm{Cu} \mathrm{K}{ }_{\alpha}$ source. The brazed samples were cut in the transverse cross-section, mounted in epoxy and polished. The interfacial microstructure was examined employing Quanta Inspect scanning electron microscopy (SEM) coupled with energy dispersive X-ray spectroscopy (EDS).

\section{Results and discussion}

X-ray diffraction (XRD) measurements were performed in the $\mathrm{Cr} / \mathrm{C}$ samples in order to monitor the evolution of carbide formation through the intermediate stages of thermal treatments. Fig. 2 shows the XRD spectra from: (a) the as deposited Cr layer on the graphite substrate, (b) the post annealed $\mathrm{Cr} / \mathrm{C}$ at $700{ }^{\circ} \mathrm{C}$ for $1 \mathrm{~h}$ and (c) the post annealed $\mathrm{Cr} / \mathrm{C}$ undergone the thermal cycle employed for the brazing process (BTC). For comparison, the XRD spectrum of the graphite substrate is presented at the bottom of Fig. 2. The strong (110) and (200) chromium peaks (Fig. 2a) show the polycrystalline structure of the as deposited film. There is no indication of carbide formation during the deposition and this would be expected as the deposition temperature was around $70{ }^{\circ} \mathrm{C}$. After annealing under vacuum for $1 \mathrm{~h}$ at $700{ }^{\circ} \mathrm{C}, \mathrm{Cr}_{7} \mathrm{C}_{3}$ has been formed at the $\mathrm{Cr} / \mathrm{C}$ interface. Longer annealing times result in an increase of the amount of the chromium carbide. The 
XRD spectrum of the $\mathrm{Cr} / \mathrm{C}$ sample, which was heat treated according to the BTC (Fig. 1), shows a coexistence of the $\mathrm{Cr}_{7} \mathrm{C}_{3}$ and $\mathrm{Cr}_{3} \mathrm{C}_{2}$ phases and that all the $\mathrm{Cr}$ has been transformed to carbides (the strong Cr Bragg peaks are not observed).

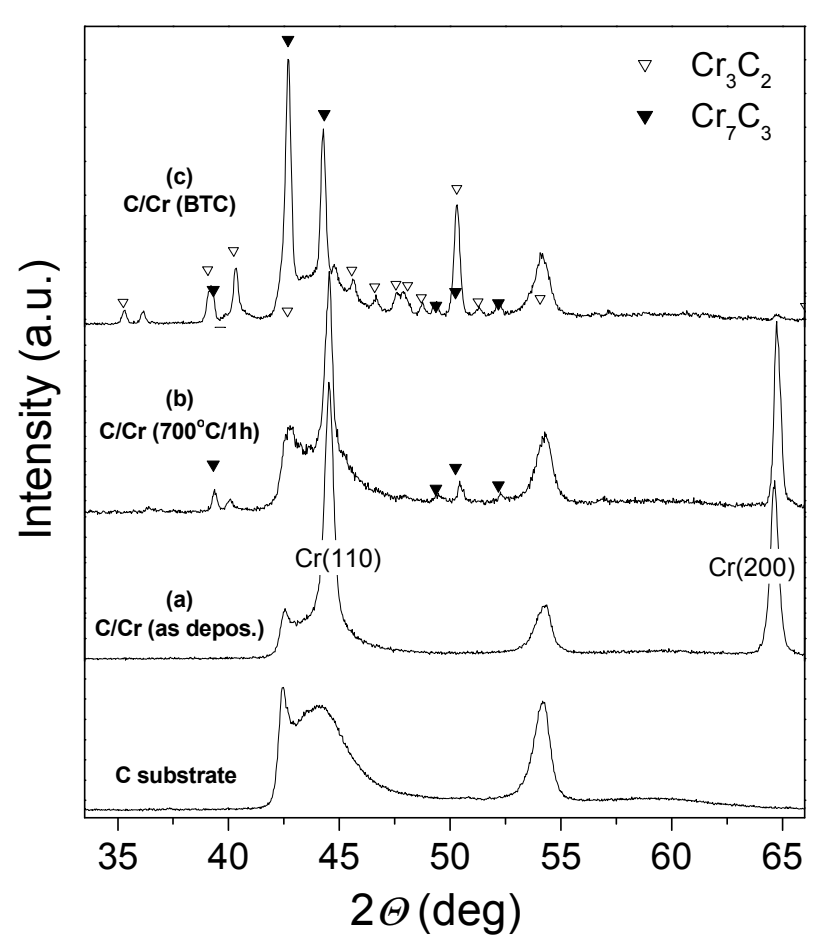

Fig. 2. X-ray diffraction spectra of the $\mathrm{Cr} / \mathrm{C}$ system at the different stages of processing: (a) as deposited, (b) annealed at $700{ }^{\circ} \mathrm{C}$ for 1 $\mathrm{h}$ and (c) after the brazing thermal cycle (BTC). Bottom spectrum refers to the graphite substrate. Triangles: $\mathrm{Cr}_{7} \mathrm{C}_{3}$ (solid) and $\mathrm{Cr}_{3} \mathrm{C}_{2}$ (open) Bragg peak positions.

SEM analysis of the cross section of the as deposited $\mathrm{Cr}$ films shows that the Cr layer follows the graphite substrate roughness and it is almost continuous. The heat treatment at $700{ }^{\circ} \mathrm{C}$ does not destroy the good surface coverage and no diffusion of $\mathrm{Cr}$ to $\mathrm{C}$ or vice versa is observed. On the contrary, the BTC heat treatment results in a strong $\mathrm{C}$ diffusion to the $\mathrm{Cr}$ layer and to the formation of chromium carbides as it has been found by the XRD measurements. Also some diffusion of the $\mathrm{Cr}$ to the graphite substrate is observed presumably through the graphite open channels.

The $\mathrm{Cr} / \mathrm{C}$ structure (deposited $\mathrm{Cr}$ and annealed for $1 \mathrm{~h}$ at $700{ }^{\circ} \mathrm{C}$ ) was brazed to a Nimonic 105 alloy using the TiCuSil filler metal and the brazing process as depicted in Fig. 1. From the SEM image of the cross section of the brazed sample, we observe a successful joining and interfaces free of cracks or other voids (Fig. 3). Also diffusion (up to around $50 \mu \mathrm{m}$ ) of the metallic elements of the filler and the deposited chromium into the graphite is observed (Fig. 4). As the brazing has been performed at a temperature where the filler metal is in a liquid form $\left(\mathrm{T}_{l i q}=900{ }^{\circ} \mathrm{C}\right)$, we have to assume that a mass transport of the filler metallic species through the graphite channels and up to its open pores (Fig. 4) has occurred.

Through this mass transport of the liquid filler, the $\mathrm{Cr}$ on the graphite surface, not being transformed to chromium carbide, is carried away up to the graphite pores (Fig. 6). During the slow cooling down $\left(1{ }^{\circ} \mathrm{C} / \mathrm{min}\right)$ from the brazing temperature, the filler metals, which have not been transported to the graphite (or to the Nimonic) and remaining at the graphite surface, are separated and form a well defined layered structure (Fig. 5). The remaining filler between the graphite and the Nimonic alloy has been depleted mainly from Ti. The Ti, having the highest melting temperature, has been separated from the Ag and forms a distinctive layer. The Ti layer is followed by a Ag layer which remains on the top of the chromium carbide layer. 


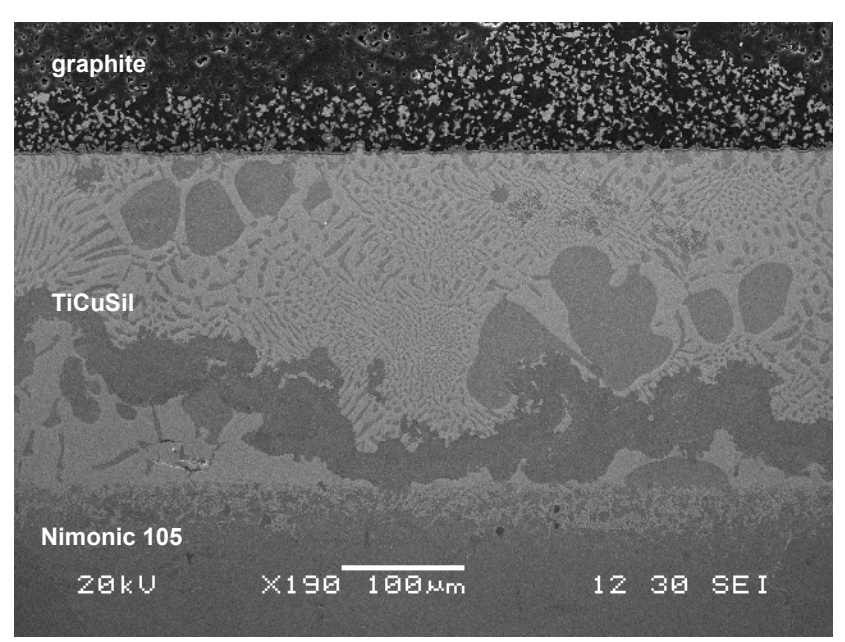

Fig.3. SEM image of the cross-section of the brazed sample at the joint.

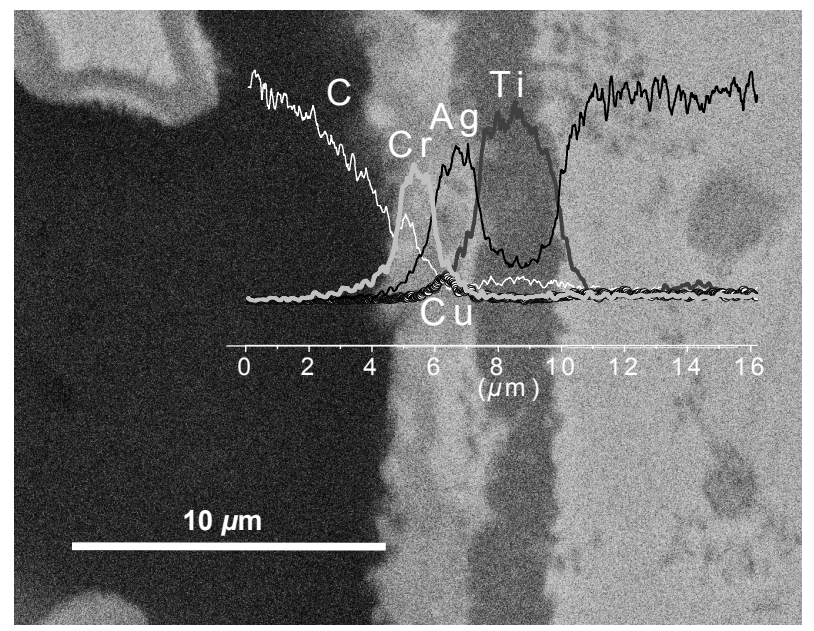

Fig. 5. EDS line scan across the graphite/filler interface.

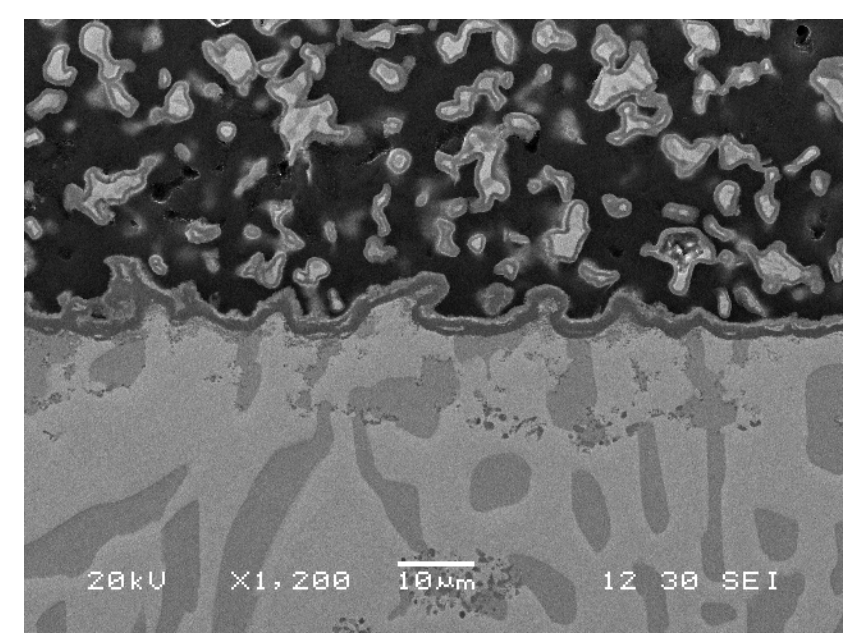

Fig.4. SEM image of the cross-section of the brazed sample at the filler/graphite interface.

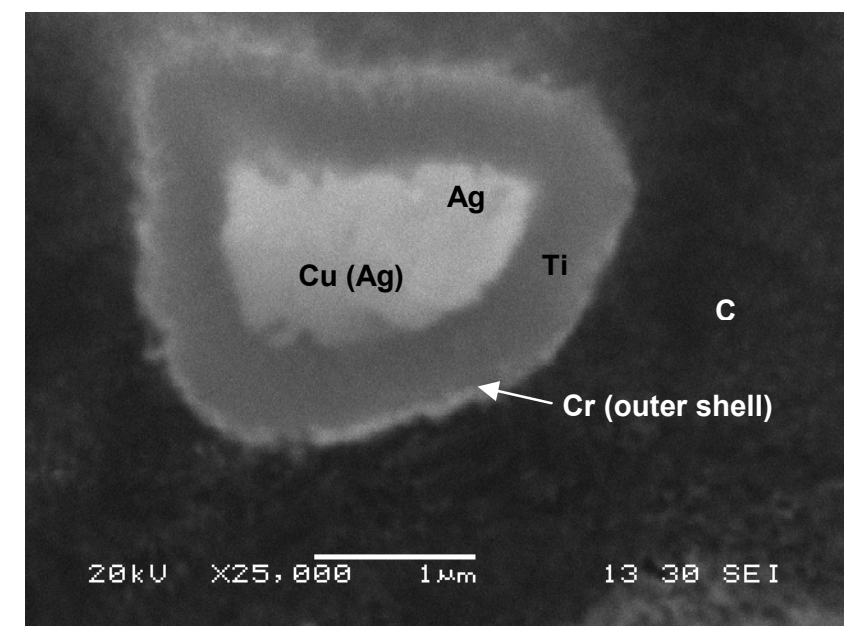

Fig. 6. SEM image of the graphite pores.

The same separation of the filler metals takes place inside the pores (Fig. 6). A thin layer (50 nm) of chromium directly coats the pores inner wall, followed by a thick layer $(0.5-1 \mu \mathrm{m})$ of titanium. These layers trace the profile of the pore shell. The core of the pore is filled by the remaining transported metallic species, copper and silver. From EDS analysis of $\mathrm{Cr} / \mathrm{C}$ samples thermally treated under the brazing thermal cycle, no extensive $\mathrm{Cr}$ diffusion into the graphite has been observed. This demonstrates that the filler metal in the liquefied state acts as an agent for the $\mathrm{Cr}$ to penetrate into the graphite. The $\mathrm{Cr}$ decorating the internal surface of the pores presumably has interacted with the graphite to form chromium carbides.

At the Nimonic side an interface layer of about $40 \mu \mathrm{m}$ thick, following the roughness of the Nimonic is formed (Fig. 7). The interface layer is a mixture of Ti (from the filler) and elements from the Nimonic alloy 105 as $\mathrm{Co}, \mathrm{Al}, \mathrm{Fe}$ and $\mathrm{Ni}$. Also separation of $\mathrm{Cu}$, in the form of inclusions, from the filler alloy is observed. Mainly Ag and less Ti of the filler diffuses deep into the Nimonic alloy. 


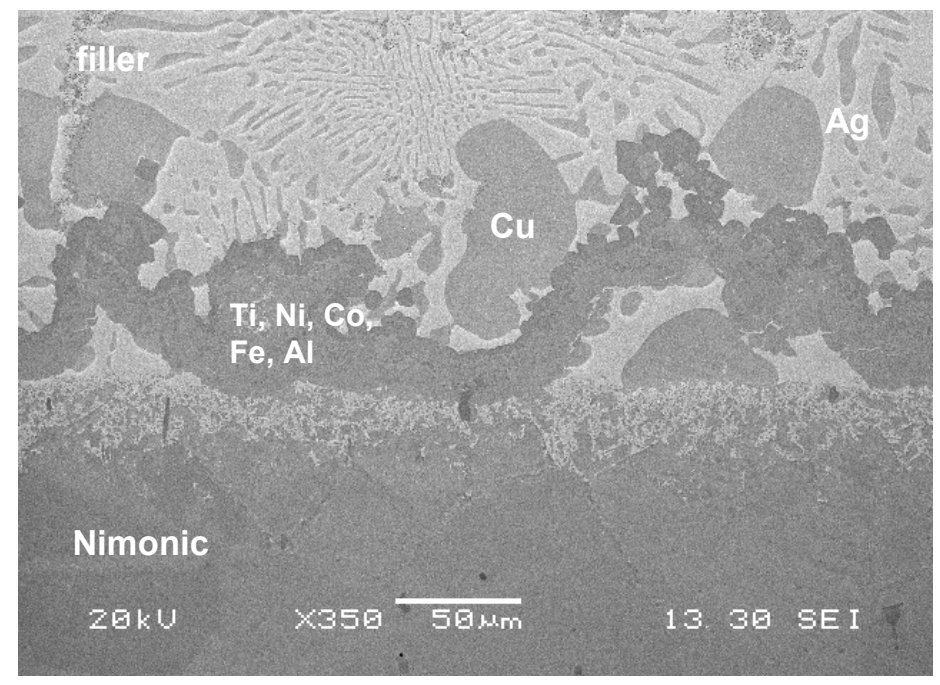

Fig. 7. SEM image of the Nimonic/filler interface.

\section{Conclusions}

A Nimonic 105 superalloy has been successfully brazed to a graphite sheet using a commercial TiCuSil paste. The interfaces between both the graphite/filler and the filler/Nimonic are free of structural imperfections such as interfacial microvoids and cracks. The graphite sheet before brazing was metallized by a sputtered $\mathrm{Cr}$ layer and subsequently annealed in order to develop a suitable structure. Part of the filler, which is in liquid form at the brazing temperature, was mass transported into the graphite substrate up to a depth of 50 $\mu \mathrm{m}$, filling its open pores. In both the graphite interface and inside its pores a layered structure of the filler metallic species and the $\mathrm{Cr}$ has been observed. The layered structures inside the pores exhibits an increasing CTE from the pore wall to its centre. The same CTE gradient is observed at the filler/graphite interface. This offers an additional advantage for high temperature applications. The microstructurally sound joint produced in this study proposes an exploitable route for technological applications and mainly in the development of optimized bonding processes of carbon-based composites to metallic components.

\section{Acknowlegments}

This work has been carried out within the framework of the Integrated European Project "ExtreMat" (contract NMP-CT-2004-500253) with financial support by the European Community. The paper only reflects the views of the authors and the European Community is not liable for any use of the information contained therein.

Also, helpful discussions and comments from Dr S. Messoloras are acknowledged.

\section{References}

[1] R. Taylor in: Comprehensive Composite Materials, 4, Elsevier Science Ltd, Boston, (2000), p.387

[2] S. Makimura, H. Hidetsugu, H. Okamura, M. Futakawa, T. Naoe, Y. Miyake, N. Kawamura, K. Nishiyama, M. Kawai: J. Nucl. Mater (2008), in press

[3] M. Ferraris, M. Salvo, C. Isola, M. Appendino Montorsi, A. Kohyama: J. Nucl. Mater. Vol. 258-263 (1998), p. 1546

[4] Y. Qin, J. Feng: Mater. Sci. Eng. A Vol. 454-455 (2007), p. 322

[5] M. Salvo, V. Casalengo, S. Rizzo, F. Smeacetto, M. Ferraris, M. Merola: J. Nucl. Mater. Vol. 357 (2008), p. 410

[6] G.N. Morscher, M. Singh, T.P. Shpargel, R. Asthana: Mater. Sci. Eng. A Vol. 418 (2006), p. 19

[7] M. Singh, T.P. Shpargel, G.N. Morscher, R. Asthana: Mater. Sci. Eng. A Vol. 412 (2005), p. 123

[8] M. Singh, R. Asthana, T.P. Shpargel: Mater. Sci. Eng. A Vol. $452-453$ (2007), p. 699 